\title{
Study of fundamental control concepts through interactive learning objects *
}

\author{
José Luis Guzman* Ramon Costa-Castelló *** \\ Sebastian Dormido** Manuel Berenguel ${ }^{*}$ \\ * Universidad de Almería, Dep. de Lenguajes y Computación, Spain \\ (e-mail: joguzman,beren@ual.es) \\ ** Universidad Nacional de Educacion a Distancia, Dep. de \\ Informática y Automática (sdormido@dia.uned.es) \\ *** Universitat Politècnica de Catalunya, Institut d'Organització $i$ \\ Control de Sistemes Industrials (ramon.costa@upc.edu)
}

\begin{abstract}
Information technology has contributed significantly to the renewal of teaching methodologies used in control systems teaching. Computer applications are becoming very popular as a support in traditional lectures and as self-learning tools. This paper describes an on-going project which tries to develop a suite of interactive learning objects composed by graphical interactive applications plus simple learning cards to cover the complete contents of an introductory control system course.
\end{abstract}

Keywords: Interactive Learning Objects, Interactivity, Sysquake, Linear Systems, Classical Control

\section{INTRODUCTION}

In recent years there has been a review of methods used for teaching and learning automatic control theory [Dormido, 2004]. This review process has introduced technology information in the learning process. Most significant results are the proliferation of numerous virtual, remote laboratories and interactive graphical applications that exploit geometrical visualization interactivity as a teaching tool[Candelas Herías and Sánchez Moreno, 2005, Kroumov et al., 2003, Dormido, 2003, Johansson and Åström, 1998]. These tools are of great relevance during traditional lectures, to support the explanation introduced by the teacher and also as self-learning tool for distance or regular students.

Classical theory is plenty of graphical interpretations and graphical methods which have been strengthened with the introduction of computers in the analysis and design of controllers. As most relevant concepts provide a graphical visualization, control theory is particularly suitable for developing interactive graphics applications. This feature has led to the development of different tools related with different topics [Candelas Herías and Sánchez Moreno, 2005]. This, include among others, tools related with Root Locus [Cywiak and Castro, 2002, Oliveira e Silva, 1998], Frequency Response [Cheever and Li, 2005], Predictive Control [Guzmán et al., 2005], Internal Model Principle [Diaz Guerra et al., 2009], Compensators for delay systems[Normey-Rico et al., 2009], PID Control [Guzmán et al., 2008a], nonlinear static analysis[Dormido et al.,

\footnotetext{
* This work is partially supported by the Spanish Ministerio de Ciencia e Innovación under projects DPI2010-21589-C05-04, DPI200761068, and DPI2007-62582.
}

2002], or mobile robotics [Guzmán et al., 2008b]. In addition, control theory, and especially classical design procedures, contain a number of approximations and tradeoff which simplify controllers and design procedures, the introduction of these concepts might be difficult from the analytical point of view, interactivity can help new students to introduce themselves in this concepts.

As previously mentioned, there exist a number of specific applications for certain topics or control techniques, but there are few applications or sets of applications which comprehensively cover an introductory course. Some examples can be found in [Longchamp, 2006, Aström and Wittenmark, 1997, Johansson and Gäfvert, 2003] which in most cases are directly related with a traditional text book. In this project a suite of interactive learning objects is being developed with the main goal to cover an introductory control course completely, the applications are being designed and implemented jointly with a documentation files. During the design of the documentation information from the application is used and taken into account, additionally several exercises following a learning-by-example paradigm are proposed to the students. In order to simplify development and maintenance, Sysquake [Piguet, 2009] is being used a development tool, and a concrete independent application for each topic is being developed.

The work is structured as follows, section 2 describes the project objectives and its structure, section 3 presents the topics addressed in the project, sections 4, 5 and 6 describe three specific examples and finally section 7 describes the goals achieved so far in the project and future work. 


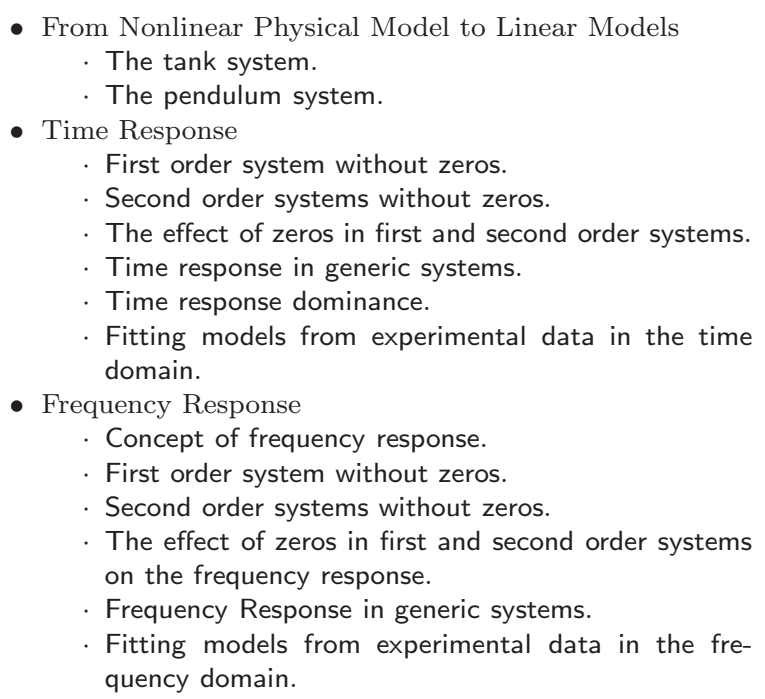

- From Physical Model to Model Parameters

- The tank system II

- The pendulum system II

- Closed-loop Systems: Stability.

- Root Locus diagram.

Nyquist criteria.

Bode criteria. Gain \& phase margin.

- Control System Design

- Lead controller in the frequency domain.

- Lag controller in the frequency domain.

- Lead controller in the root locus.

- Lag controller in the root locus.

PID design by pole placement.

- Controlling Physical Systems

. The tank system III

The pendulum system III

Table 1. List of Applications contained in the project

\section{PROJECT GOALS: COMPONENTS AND APPLICATION STRUCTURE}

Most engineering students take an introductory course on control, in most engineering curricula this corresponds to a semester. This is usually little time to obtain a deep knowledge in any material, and particularly in control. Introductory courses contain a number of new concepts to be learned, so it is a challenging task for most teachers. It is the goal of this project to provide tools for teacher and students to success in this task.

Interactivity and graphical visualization can contribute to short cut the learning process and can help to make traditional lectures more attractive and interesting for students. As a consequence an introductory course on classical control has been designed from scratch, more than the concepts to teach this new design has focused on how to teach every concept. Once relevant concepts have been identified, how to visualize them has been studied and how to formulate learning-by-example problems has been analyzed. After the analysis of a complete course a set of computer applications have been designed and currently most of them are under development.

A secondary goal of the project is to adapt the course to the Bologna process and the European Credit Transfer System (ECTS). One of the secondary objectives of this process is to enhance the lifelong study and potentiate the individual student work. A set of interactive materials can contribute to this goal, so the applications have been designed trying also to achieve this goal. From the student point of view, each concept application is composed by

- A graphical and interactive application (almost self explained) which visualize it. All elements are completely interactive in order to potentiate the interaction with it.

- The application contains a preprogrammed examples especially designed to illustrate some particular phenomena behind the concept or particular cases.
- Each application is accompanied by a small dossier describing the concept in a formal and analytical way. It is not the goal of the dossier to substitute the textbook; as a consequence the theoretical concept is the minimum which allows understanding the application behavior. The dossier contains links to specific textbooks (indicating chapter and pages) so the students can improve their knowledge in the field.

- Although the application functionalities can be understood by playing with the application, the dossier contains a brief user manual which describes in detail all the application functionalities.

- The dossier or learning card contains different exercises to be developed using the application. The goal of these examples is to guide the student learning steps so that he does not spend too much time and forces him to look at the important points. The exercises try to follow a learning by discovery paradigm and try to combine qualitatively knowledge obtained by interacting with a more quantitative knowledge obtained by solving selected exercises.

From the teacher point, that in our case acts also as developer:

- Sysquake has been used as development tool due to its powerful programming language, quite close the de facto standard, MATLAB. Interactive is completely integrated in the language. This provides a high-level development framework which is very convenient for non professional programmers like most of us.

- Most applications contain may common components such as input signal, zero/pole editors, or connection to the dossier between others. All these elements have being grouped in a library used by all the applications. This simplifies the development and maintance of the complete set of applications.

- The applications can be distributed in source code (the students need to install Sysquake previously) or in a compiler manner (no preinstallation is needed). In both cases the applications are not weighted so it can be easily distributed. 


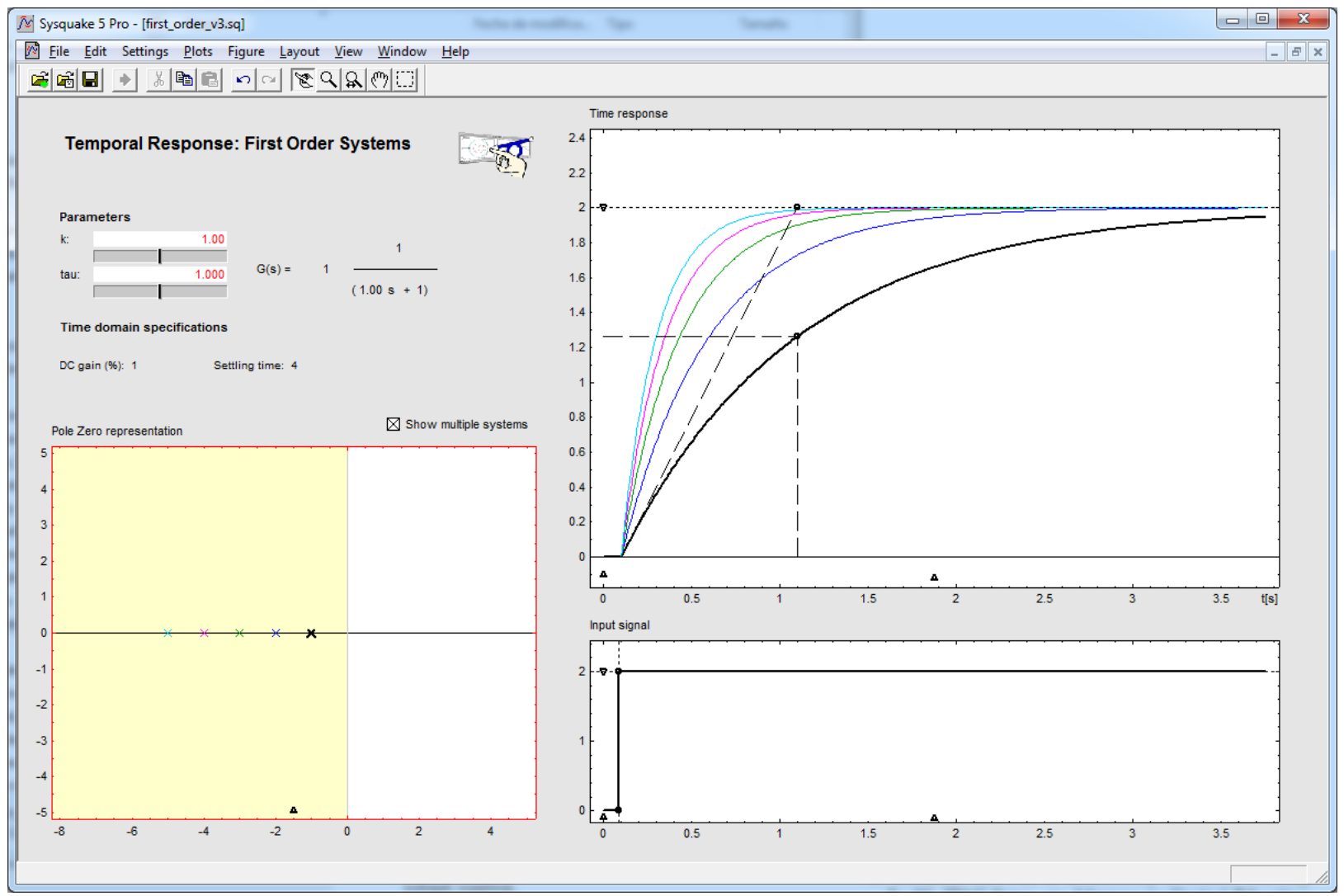

Figure 1. First order systems time response

\section{CONTENTS}

The course contents are designed based on those concepts needed for an introductory course on classical control techniques, specially those which can be easily displayed and interactuated. Table 1 contains the list of applications grouped by topics. The applications can be grouped in the following groups.:

- From Nonlinear Physical Model to Linear models. This group is composed by a couple of applications which describe how to relate nonlinear physical model, usually nonlinear, with the linear model used in basic control techniques. Additionally these applications are used to describe the linear behavior concept around an operating point.

- Time Response. This group contains a set of applications intended to illustrate the time response of linear models. Also an application which shows how to tune models to experimental data is included.

- Frequency Response. This group contains a set of applications intended to illustrate the frequency response concept, how it is displayed and the which is the frequency response of linear models.

- From Physical Model to model parameters. The examples illustrate the relationship of the physical system with some elements of models such as poles, zeros, temporary response, frequency response.

- Closed-loop Systems : Stability. Fundamental stability analysis techniques are introduced in this group of applications.

- Control System Design. Different controller design techniques are introduced in this group.
- Controlling Physical Systems. Different controllers are analyzed for two specific physical systems are analyzed in this group of applications.

As an example, three specific applications are described in the following sections. Section 4 describes the application designed to illustrate the time response of first order linear systems, Section 5 describes a one tank plant application, and finally Section 6 introduces the application related with the frequency response of second order systems.

\section{TIME RESPONSE: FIRST ORDER SYSTEMS WITHOUT ZEROS}

In conventional control courses the transfer function of first order systems is represented in canonical form as:

$$
G(s)=\frac{k}{\tau s+1}
$$

that is characterized by the static gain $k$ and time constant $\tau$. In our project a didactic tool has been designed to study this time response (see Figure 1). The tool is combined with a dossier or learning card similar to the one partially shown in Figure 2, which describes the theoretical concepts behind the graphical representation. As can be seen, the interactive tool incorporates different graphical representations of a first order system which can be interactively modified by the users. The learning card shows a basic theoretical explanation, the used bibliography, access to the interactive tool, a brief explanation of how to use and interact with the tool, and proposed exercises to promote the students' self learning using the tool. 
Temporal response of first order linear systems

\section{Theory}

This card analizes the time response of linear time invariant first order systems without zeros. These systems constitute the most simple dynamics coming from first order differential equations as $\tau \frac{d y(t)}{d t}+y(t)=k u(t)$, where $y(t)$ and $u(t)$ are the output and input of the system respectively. The corresponding transfer function can be written as:

$$
G(s)=\frac{k}{\tau s+1}
$$

where

- $k$ is the static gain

- $\tau$ is the time constant (the system pole is $s=-\frac{1}{\tau}$ ).

The transfer function represents the system dynamics around an operating point. Usually, the time that traditionally is a unitary step $\left(U(s)=\frac{1}{s}\right)$. Thus, the unitary step time response of a first order system is given by:

$$
y(t)=\mathcal{L}^{-1}\left\{G(s) \frac{1}{s}\right\}=k\left(1-e^{-\frac{1}{\tau} t}\right) .
$$

that can be also obtained solving the differential equation with $u(t)=\left\{\begin{array}{l}1, t>0 \\ 0, t \leq 0\end{array}\right.$

The system output performance depends on the sign of $\tau$ :

- If $\tau>0$, the signal is bounded and thus the system is stable.

- If $\tau<0$, the system is unstable.

Note that if $\tau=0$ the system is static. The name of the time constant $\tau$, comes from the fact that this parameter gives an idea of the speed of the transient response of the system. The higher $\tau$, the slowre the response. Thus,

- for $t=\tau$, the system output reaches the $63 \%$ of the final value,

- for $t=3 \tau$, the system output reaches the $95 \%$ of the final value,

- for $t=4 \tau$, the system output reaches $98 \%$ of the final value.

stem output change and input change in steady state. The slope of the system response at $t=0$ is $\frac{k}{7}$.

\section{References}

- Katsuhiko Ogata. Modern Control Engineering (in Spanish). Pearson Prentice Hall. 4t Edition. ISBN: 84-205-3678-4. [Capítol: 5.2, Pàgines: 221-224]

Figure 2. Simple learning card example

The tool presents in its lower left part the $s$-plane, Pole Zero representation, showing the location of the poles of the represented systems; in the upper right part the time responses are plotted, Time Response; in the lower right part the input step is shown, Input signal; and finally, in the upper left part the values of the parameters and the transfer function are shown, Parameters, as well as the indexes characterizing the time response of the selected system Time domain specifications, that in this case are the static gain and settling time (10\%-90\%). All these plots are interactive: in the $s$-plane it is possible to move the pole position; in the time response figure the initial slope and final value of the different responses can be changed; in the input signal graph it is possible to modify the amplitude and activation instant and finally, the system parameters can be changed quantitatively. More details are given in Figure 2.

\section{FROM NONLINEAR PHYSICAL MODEL TO LINEAR MODELS: THE TANK SYSTEM}

Although more generic theory exists, most industrial controllers and most popular control theory in based on linear control theory. More specifically, input/ouput formulation

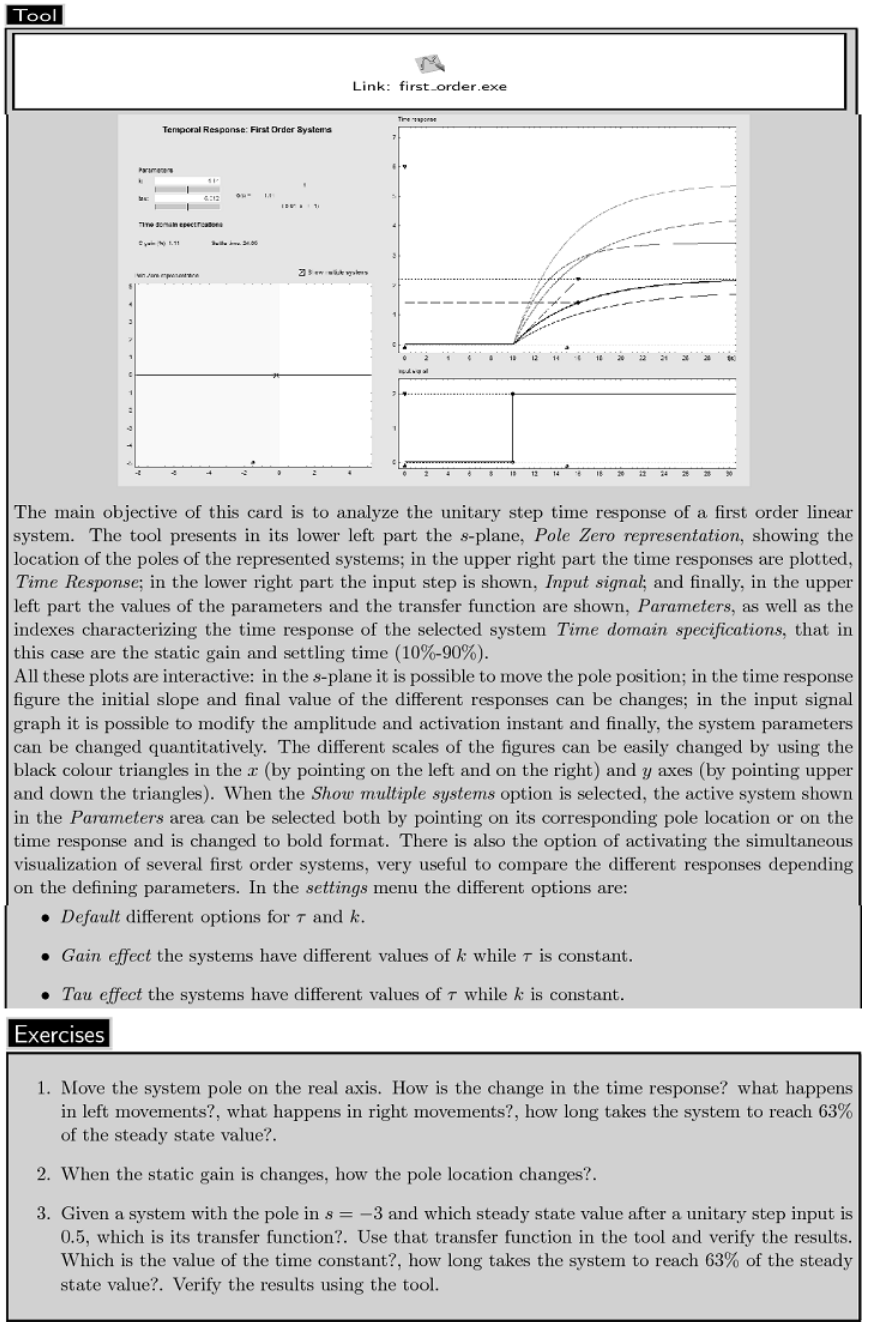

based on Laplace transform is by far the control theory used to introduce students in the automatic control field. Unfortunately, most systems behavior is described by physical laws which are in general nonlinear. As a consequence the equations describing the system behavior must be linearized before applying the linear control techniques to them. This linearization is usually done by approximating the nonlinear vector field by its Taylor expansion around an equilibrium point. This approximation depends on the system parameters and the specific equilibrium point, as a consequence it is only correct around the equilibrium point.

Level control in a tank systems [Johansson, 2000] or a single tank is a very popular control plant. In this application (see Figure 3) it is possible to compare the openloop time response obtained with the nonlinear control set and the one obtained with the approximated linear system. It is possible to analyze it in different equilibrium points an for different geometrical tank parameters, this allows to obtain a quantitative and qualitative feedback from the validity range of these models. The system parameters can be interactively changed by interacting with the tank geometrical description. The dossier (not shown) contains a detailed description of the nonlinear model and it linearizing procedure. 


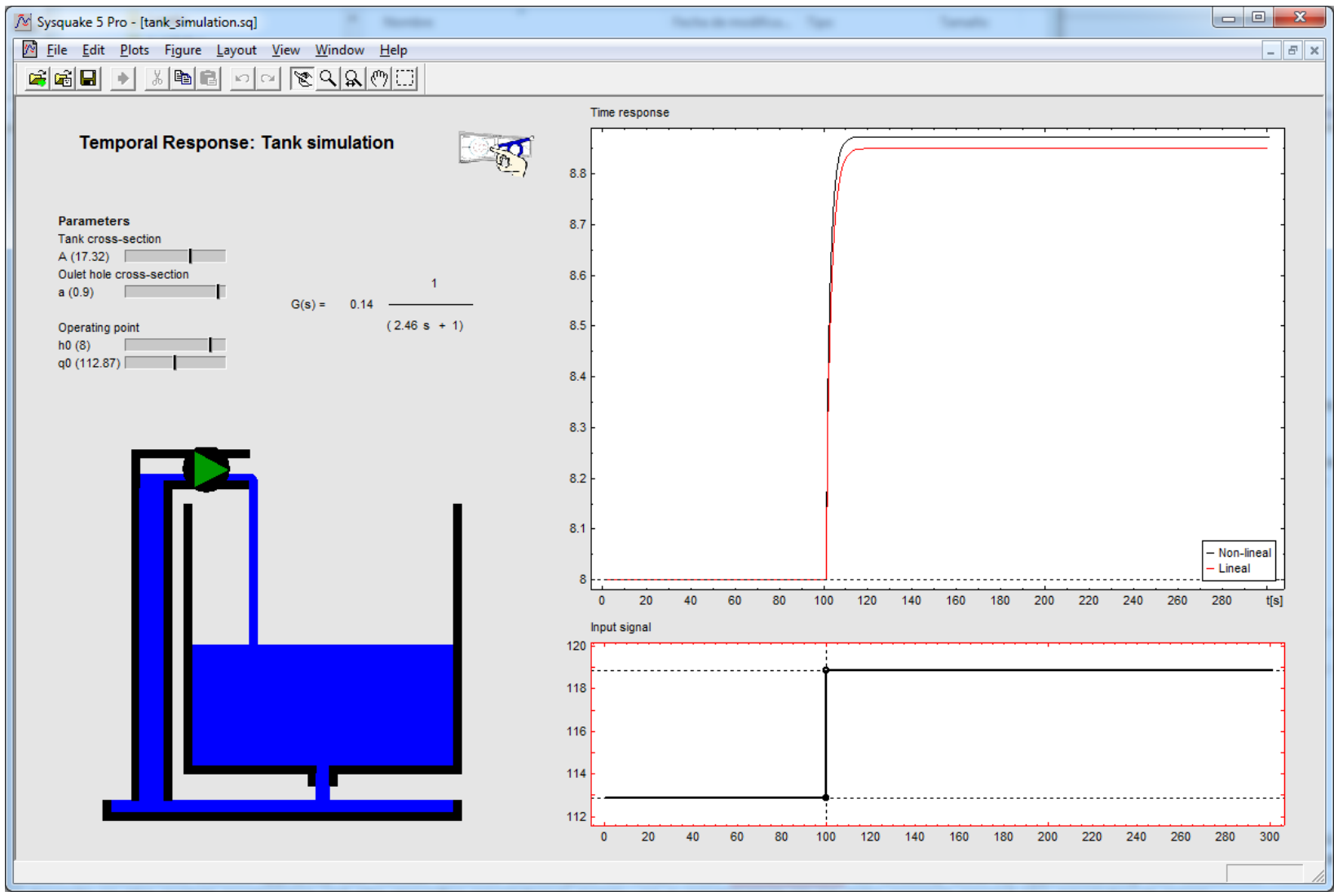

Figure 3. From Physical Systems to Linear Models : The Tank System

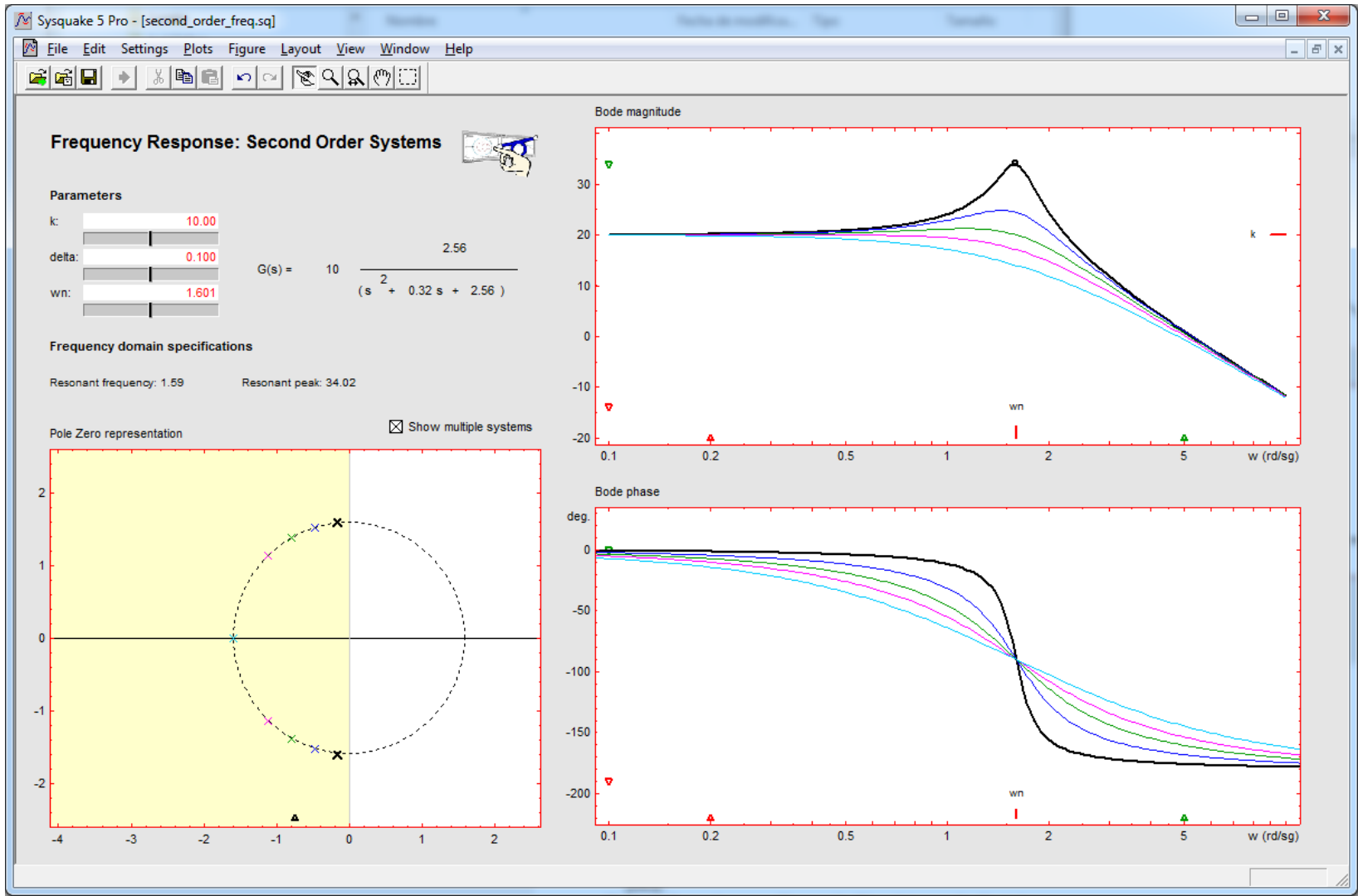

Figure 4. Second order systems frequency response 


\section{FREQUENCY RESPONSE: SECOND ORDER SYSTEMS WITHOUT ZEROS}

A key phenomena in linear systems is frequency response, it is very important to understand the system behavior in open-loop in addition it is also very important to the study the closed-loop stability from open-loop information. As a consequence most introductory courses spend some time analyzing and studying this phenomena. As introduced in previous section, this is usually done analyzing firstly the first and second order systems frequency response and latter showing how to obtain the frequency response of a generic system from the combination of its decomposition in first and second order systems. Our project follows a similar scheme, very simple tools have been designed to study the first and second order systems frequency responses and a more sophisticated for generic systems. Figure 4 shows the interactive tool designed to study the second order order frequency response (the learning card is not shown).

In the tool shown in Figure 4 it is possible to display the exact frequency response for a second order canonical system given by:

$$
G(s)=\frac{k \omega_{n}^{2}}{s^{2}+2 \delta \omega_{n} s+\omega_{n}^{2}}
$$

and also its asymptotical approximation. Several approximations can be used in the phase plot, this allows to understand how these approximations work. The asymptotical approximation allows to easy generate frequency response approximations which allow to construct simple mental models of it.

\section{CONCLUSIONS AND FURTHER WORKS}

This paper describes a project which aims to develop a set of interactive learning objects for an introductory automatic control course. These applications have been designed to support the theoretical lectures given by the teacher and the self-learning process followed by the student. The tools are grouped in separate modules according to the specific topic.

The interactive learning objects allow the students to concentrate on studying without any necessity to learn any specific programming language like MATLAB. Its interactivity makes the learning process more attractive to the students.

Once this project is complete it is the author's intention to extend its contents to other field like digital control and robust control.

\section{REFERENCES}

K. J. Aström and B. Wittenmark. Ccsdemo. Technical report, Department of Automatic Control. Lund Institute of Technology, 1997.

Francisco A. Candelas Herías and José Sánchez Moreno. Recursos didáctivos basados en internet para el apoyo a la enseñanza de materias del área de ingeniería de sistemas y automática. Revista Iberoamericana de Automática e Informática Industrial, 2(2):93-101, Abril 2005 .
Erik Cheever and Yue Li. A tool for construction of bode diagrams from piecewise linear asymptotic approximations. The International Journal of Engineering Education, 21(2):335-340, 2005.

M. Cywiak and M. Castro. Simple technique for root locus plotting. Revista Mexicana de Física, 48(6):556-564, December 2002.

Lluis Diaz Guerra, Germán A. Ramos Fuentes, Hector Vargas, and Ramon Costa-Castelló. A virtual/remote laboratory to illustrate the internal model principle for periodical signals. In The 8th IFAC Symposium on Advances in Control Education (ACE2009), pages 1-6, Kumamoto, Japan, October 21-23, 2009.

S. Dormido. The role of interactivity in control learning. In 6th IFAC Symp. on Advances in Control Education, pages 11-22, 2003.

S. Dormido. Control learning: Present and future. Annual Reviews in Control, 28(1):115-136, 2004.

S. Dormido, F. Gordillo, S. Dormido-Canto, and J. Aracil. An interactive tool for introductory nonlinear control systems education. In 15th IFAC World Congress b '02, pages 11-22, Barcelona, Spain, 2002.

J.L. Guzmán, M. Berenguel, and S. Dormido. Interactive teaching of constrained generalized predictive control. IEEE Control Systems Magazine, 25(2):52-66, 2005.

J.L. Guzmán, K.J. Åstrom̈, S. Dormido, T. Hägglund, M. Berenguel, and Y. Piguet. Interactive learning modules for PID control. IEEE Control System Magazine, 28(5):118-134, 2008a.

J.L. Guzmán, F. Rodríguez, M. Berenguel, and S. Dormido. Robotics and Autonomous Systems, 56(5), 2008b.

K.H. Johansson. The quadruple-tank process: A multivariable laboratory process with an adjustable zero. IEEE Transactions on Control Systems Technology, 8(3):456465, 2000.

M. Johansson and M. Gäfvertand K. J. Åström. Interactive tools for education in automatic control. IEEE Control Systems Magazine, 18(3):3340, 1998.

Mikael Johansson and Magnus Gäfvert. Ictools - interactive learning tools for control. Technical report, Department of Automatic Control. Lund Institute of Technology, 2003.

Valeri Kroumov, Keishi Shibayama, and Akira Inoue. Interactive learning tools for enhancing the education in control systems. In $33^{\text {rd }}$ ASEE/IEEE Frontiers in Education Conference, Boulder, CO, 5-8 November 2003.

Roland Longchamp. Comande Numériques de Systè̀mes Dynamiques. Cours d'Automatique. Presses Polytechniques et Universitaires Romandes, Laussane, 2006. ISBN 2-88074-642-6.

J. Normey-Rico, J.L. Guzmán, S. Dormido, M. Berenguel, and E.F. Camacho. An unified approach for DTC design using interactive tools. Control Engineering Practice, 17:1234-1244, 2009 .

Tomás Oliveira e Silva. Automatic generation of root locus plots. Revista do DETUA, 2(3):273-276, September 1998.

Y. Piguet. SysQuake 5: User Manual. Calerga Sàrl,, Laussane, Switzerland, 2009. 